\title{
Determination of Damage in Reinforced Concrete Frames with Shear Walls Using Self-Organizing Feature Map
}

\author{
Mehdi Nikoo, ${ }^{1}$ Lukasz Sadowski, ${ }^{2}$ Faeze Khademi, ${ }^{3}$ and Mohammad Nikoo ${ }^{4}$ \\ ${ }^{1}$ Young Researchers and Elite Club, Ahvaz Branch, Islamic Azad University, Ahvaz, Iran \\ ${ }^{2}$ Faculty of Civil Engineering, Wroclaw University of Science and Technology, Wybrzeze Wyspianskiego 27, 50-370 Wroclaw, Poland \\ ${ }^{3}$ Civil and Environmental Engineering Department, Illinois Institute of Technology, Chicago, IL 60616, USA \\ ${ }^{4}$ SAMA Technical and Vocational Training College, Islamic Azad University, Ahvaz Branch, Ahvaz, Iran
}

Correspondence should be addressed to Łukasz Sadowski; lukasz.sadowski@pwr.edu.pl

Received 6 January 2017; Accepted 13 April 2017; Published 15 May 2017

Academic Editor: Erich Peter Klement

Copyright (C) 2017 Mehdi Nikoo et al. This is an open access article distributed under the Creative Commons Attribution License, which permits unrestricted use, distribution, and reproduction in any medium, provided the original work is properly cited.

\begin{abstract}
The paper presents the use of a self-organizing feature map (SOFM) for determining damage in reinforced concrete frames with shear walls. For this purpose, a concrete frame with a shear wall was subjected to nonlinear dynamic analysis. The SOFM was optimized using the genetic algorithm (GA) in order to determine the number of layers, number of nodes in the hidden layer, transfer function type, and learning algorithm. The obtained model w as compared $w$ ith linear r egression (LR) a nd nonlinear regression (NonLR) models and also the radial basis function (RBF) of a neural network. It was concluded that the SOFM, when optimized with the GA, has more strength, flexibility, and accuracy.
\end{abstract}

\section{Introduction}

Damage to concrete structures mainly occurs because of inadequate management, incorrect maintenance, overloading, exposure to chemical components, climatic factors, and also extra loads such as earthquakes [1]. As mentioned by Nikoo et al. [2], earthquakes are the most devastating of these factors. Their destruction mechanism can cause extraordinary damage to a structure. In the last few years, much attention has been given to the use of artificial neural networks (ANNs) for solving various civil engineering problems [3-8].

In the self-organizing feature map (SOFM), cells are organized in various sensual areas with regular and significant computational maps $[6,9]$. As described by Kohonen [9], processor units are placed within the nodes of a onedimensional (or more) network and are regulated in a competitive learning process $[9,10]$. Therefore, the SOFM can be seen as a topographic map for input models, in which the units' locations correspond to the inherent features of the input models. Competitive learning is applied in such networks, and in each step the units compete in order to be activated. At the end of the initial step of this competition only one unit wins and its weights are changed differently when compared to the weights of other units. This kind of learning is called unsupervised learning [6]. In previous papers, the SOFM was described in more detail $[6,10]$.

In the genetic algorithm (GA), chromosomes with high competence have a higher chance of repeating in the selected population of the replication process. The basic operators of the GA are reproduction, crossover, and mutation [11]. The GA ends when certain criteria, such as a certain number of generations or the average standard deviation performance of individuals, are fulfilled [12].

The main objective of this study was to evaluate the abilities of the SOFM in determining damage in reinforced concrete frames with shear walls. The SOFM was optimized using the GA in order to determine the number of layers, number of nodes in the hidden layer, transfer function type, and learning algorithm. The obtained model was compared with linear regression (LR), nonlinear regression (NonLR), and the radial basis function (RBF) of a neural network. 
TABLE 1: Typical damage range in concrete reinforcement frames [13].

\begin{tabular}{lcc}
\hline Number & Park \& Ang index value & Type of damage \\
\hline 1 & $D \leq 0.1$ & Without any damage or minor cracking \\
2 & $0.1 \leq D \leq 0.25$ & Minor damage/cracking across the structure \\
3 & $0.25 \leq D \leq 0.4$ & Moderate damage, severe cracking \\
4 & $0.4 \leq D \leq 1$ & Sever damage, crushing of concrete and reinforcement protrusion \\
5 & $D \geq 1$ & Structural collapse \\
\hline
\end{tabular}

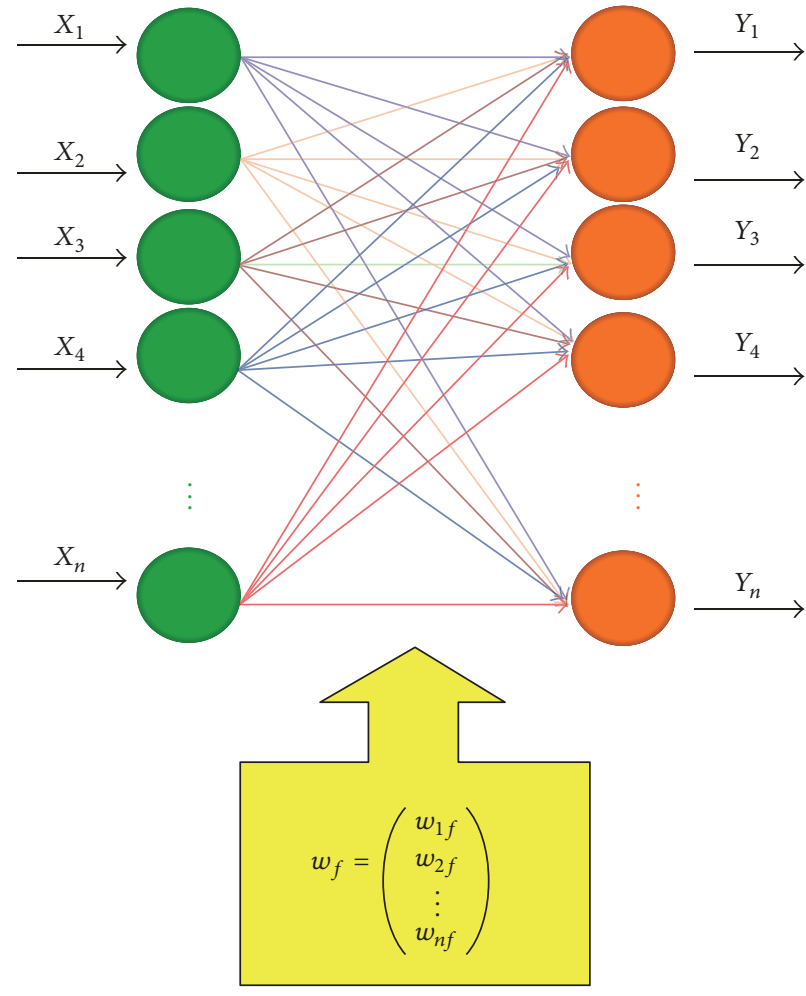

(a)

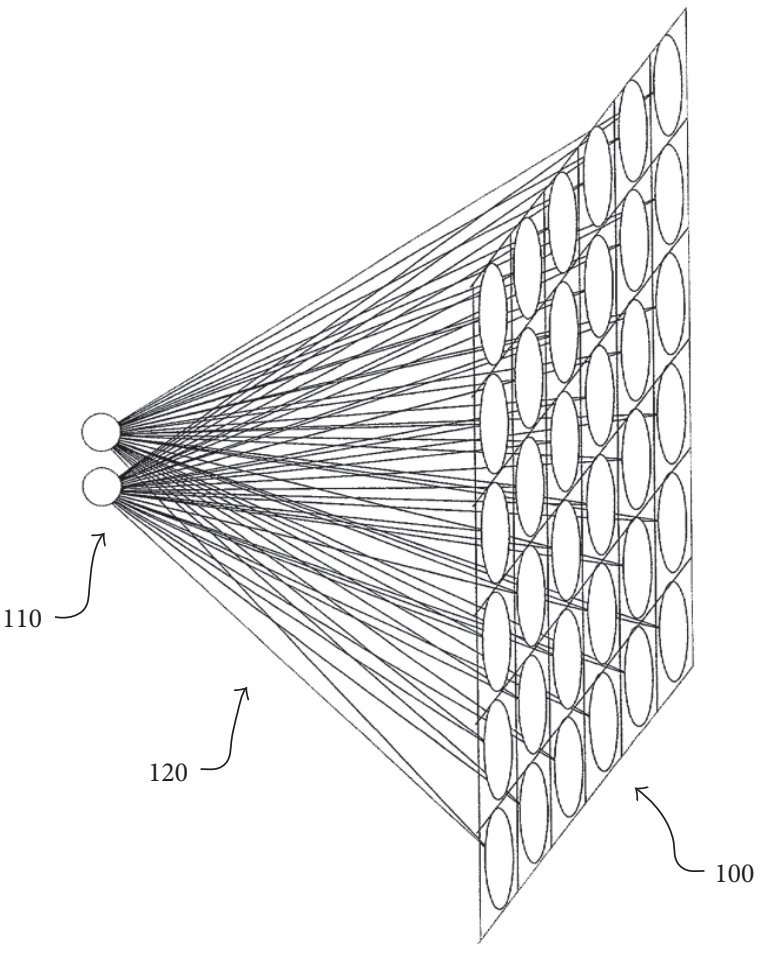

(b)

FIGURE 1: Structural model of (a) a one-dimensional network [9] and (b) a two-dimensional network [14].

\section{A Short Description of the Self-Organizing Feature Map (SOFM)}

In the SOFM, the competitive learning method is used for training and is based on specific characteristics of a developed human brain. The cells in the human brain are organized in various sensual areas with regular and significant computational maps $[6,9]$.

In the SOFM, processor units are placed within the nodes of a one-dimensional or two-dimensional network (Figure 1). These units are regulated in a competitive learning process and compared to the input models $[9,10]$. Therefore, the SOFM can be seen as a topographic map for the input models, in which the units' locations correspond to the inherent features of the input models. Competitive learning is applied in such networks, and in each step the units compete in order to be activated. At the end of the initial step of this competition, only one unit wins and its weights are changed differently when compared to the weights of other units. This kind of learning is called unsupervised learning [6].

\section{The Park and Ang Damage Index}

One of the most useful methods proposed for quantifying the calculation of damage in concrete structures is the Park and Ang model. As mentioned by Valles et al. [13], it is defined as follows [15]:

$$
D=\frac{\delta_{m}}{\delta_{u}}+\frac{\beta}{\delta_{u} \cdot P_{y}} \int d E_{h}
$$

where

$\delta_{m}$ is the maximum response of deformation under seismic load.

$P_{y}$ is the calculated yield strength.

$\delta_{u}$ is the ultimate deformation under uniform loading.

$\int d E$ is the hysteric absorbed energy.

$\beta$ is the resistance reduction parameter according to hysteric energy.

The Park and Ang index value is between 0 and 1 . The damage range is shown in Table 1. 


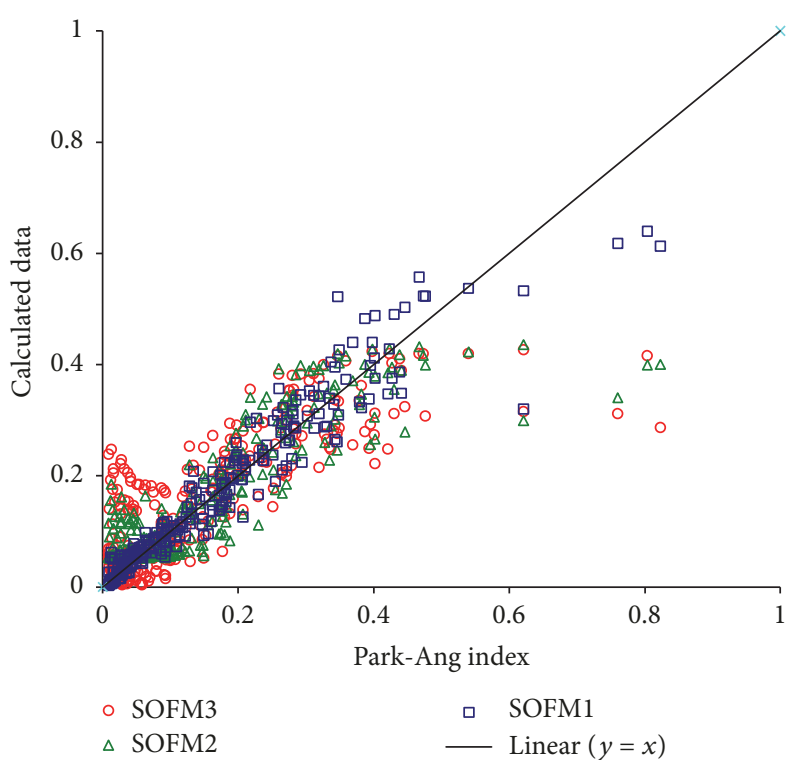

(a)

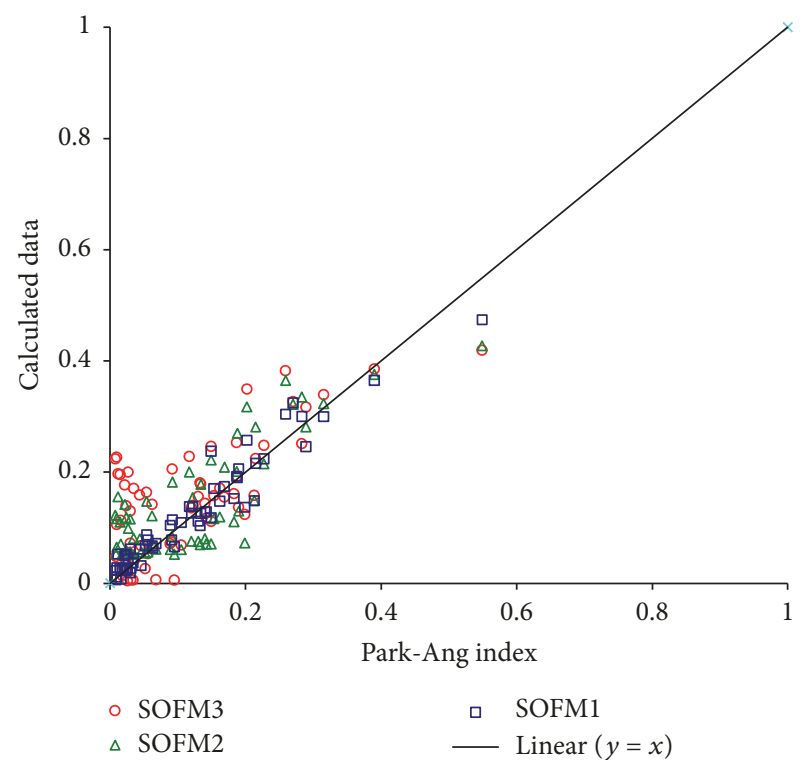

(b)

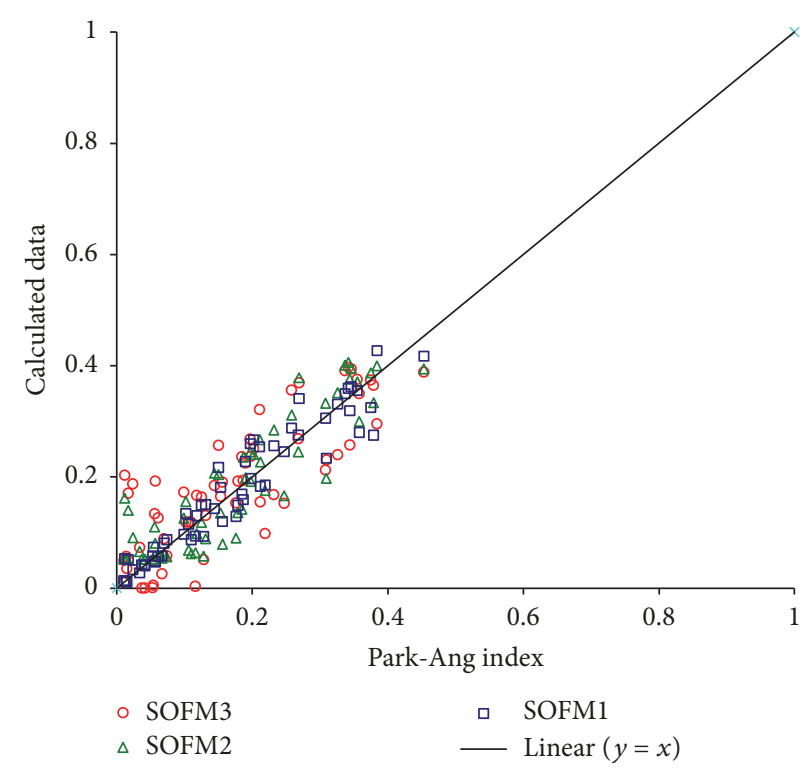

(c)

FIgURE 2: Comparison of the Park and Ang damage index and calculated data for (a) training, (b) validation, and (c) testing.

\section{Experimental Setup}

To determine the distribution function for the Park and Ang damage index, a concrete frame with a shear wall was selected. Lateral loading of the mentioned structure was then applied. In the next step, the structure was designed. The data associated with reinforced concrete frames with shear walls is listed in Table 2.

One of the main parameters influencing the input energy of structures is the earthquake accelerogram applied in seismic analysis. The extent of input energy applied to the structure is more dependent on input mapping than its structural characteristics [2]. In this research, thirty earthquakes were used for nonlinear dynamic analysis, as listed in Table 3.
After the analysis, the overall Park and Ang damage index was extracted using version 4.0 of IDARC $2 \mathrm{D}$ software.

The input parameters in this research include the following: peak ground acceleration (PGA); input time of the earthquake to a structure; time; frequency; input acceleration to the building (Acc); and also displacement. The output parameter is the Park and Ang damage index. Table 4 represents the statistical characteristics of the parameters.

\section{Experimental Results}

5.1. Performance Evaluation of the SOFM. Three Kohonen ANNs (Square, Line, and Diamond) were employed in this 
TABLE 2: Data associated with reinforced concrete frames with shear walls $[2,16]$.

\begin{tabular}{lc}
\hline Frame & $\begin{array}{c}\text { Special reinforced concrete } \\
\text { with a shear wall }\end{array}$ \\
\hline $\begin{array}{l}\text { Height of each story } \\
\text { Bay of each frame }\end{array}$ & $3.2 \mathrm{~m}$ \\
$\begin{array}{l}\text { Dead load at roof } \\
\text { Live load at roof }\end{array}$ & $500 \mathrm{mg} / \mathrm{m}^{2}$ \\
Dead load at stories & $175 \mathrm{~kg} / \mathrm{m}^{2}$ \\
Live load at stories & $500 \mathrm{~kg} / \mathrm{m}^{2}$ \\
Earthquake danger & $200 \mathrm{~kg} / \mathrm{m}^{2}$ \\
Ratio of steel $(\rho)$ in & Areas with a relatively high \\
building columns & risk \\
Twenty-eight day resistance & $0.015 \leq \rho \leq 0.035$ \\
of the concrete cylindrical & \\
sample & $f^{\prime}=240 \mathrm{~kg} / \mathrm{cm}^{2}$ \\
Flow stress in steel & \\
Shear wall & $f_{y}=3000 \mathrm{~kg} / \mathrm{cm}^{2}$ \\
\hline
\end{tabular}

research for the SOFM. From 412 sets of data, 70\% (288 sets) were used for training, $15 \%$ (62 sets) were used for validation, and 15\% (62 sets) were used for testing of the ANN. Different stimulation functions, including LinearTanhAxon, LinearAxon, and TanhAxon, were used. Table 5 shows the characteristics of the selected SOFM models.

Table 6 presents the optimized structure of the SOFM models for training, validation and testing. Table 7 presents the statistical results of different models in the SOFM. As can be seen from these tables, the SOFM1 model enjoys the highest values of the correlation coefficient $R^{2}$ for prediction of the Park and Ang damage index for training, validation, and testing.

Comparison of the Park and Ang damage index and calculated data for training, validation, and testing for each of the laboratory samples is presented in Figure 2.

The obtained values of correlation coefficient $R^{2}$ for the Park and Ang damage index for the SOFM1 model were $0.9330,0.9216$, and 0.9221 for training, validation, and testing, respectively. Additionally, the values of mean absolute error (MAE), mean square error (MSE), and root mean square error (RMSE) are less than those for the two other models. Considering the above, MSE versus epoch for the SOFM1 model is presented in Figure 3.

Considering the above, the best ANN for adaptation of input data is the SOFM with a $5 \times 5$ structure (Figure 4 ).

In addition, the impact of distances and weights of the neighborhood in a $5 \times 5$ structure in the SOFM1 model is presented in Figure 5.

\subsection{Comparison of Selected SOFM Models}

5.2.1.Linear Regression (LR). First, linear regression (LR) was used [15]. LR models are based on a data oriented technique, where the collected data is directly associated with each other. The process behind this data is not considered. In a specific

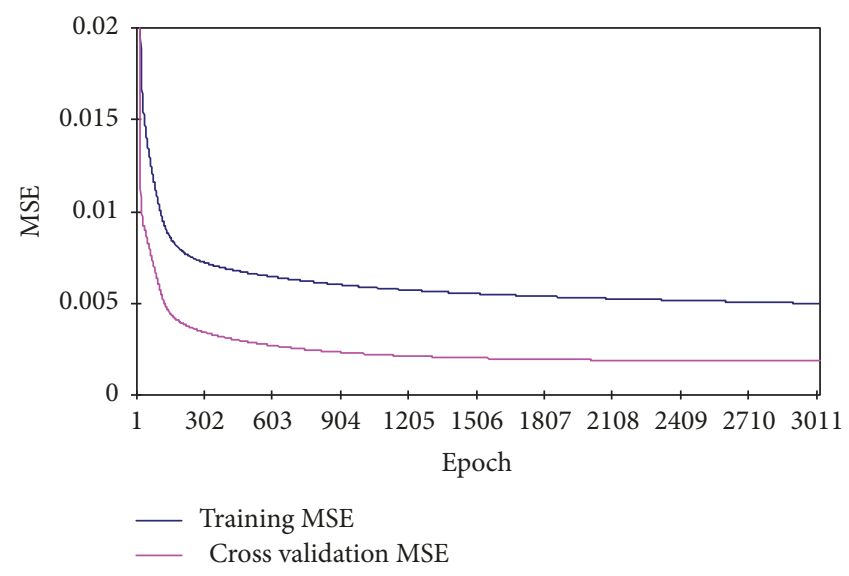

FIGURE 3: MSE versus epoch in training and validation of the SOFM1 model.

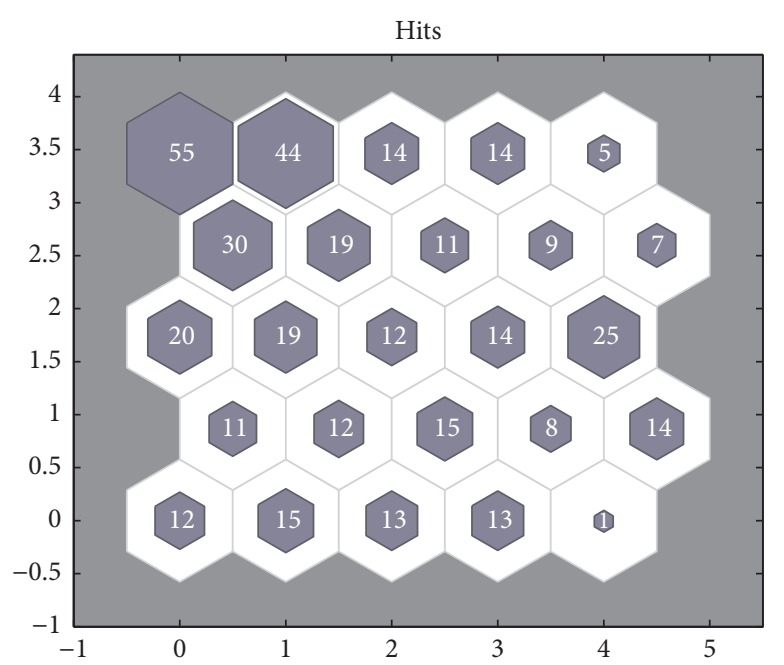

FIGURE 4: Structure for the adaptation of input data in training and validation of the SOFM1 model.

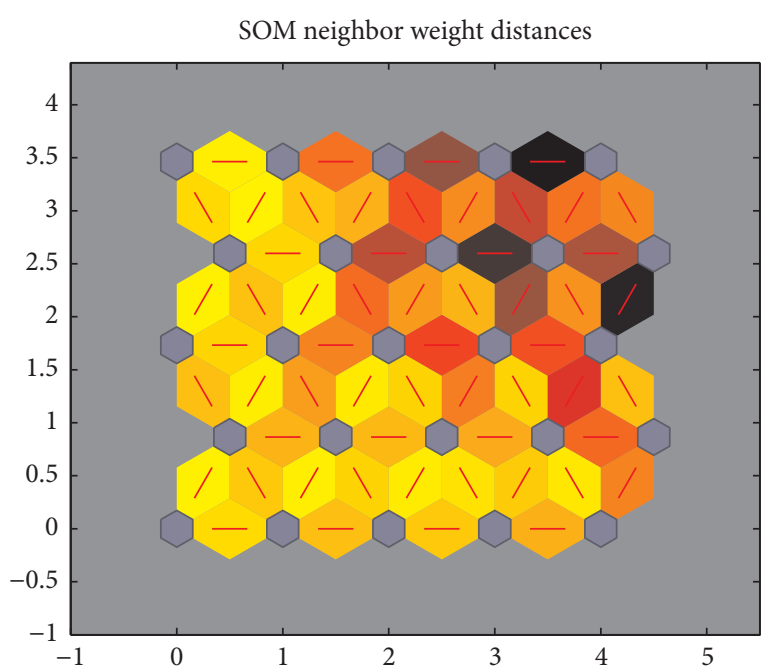

FIgURE 5: The impact of distances and weights of the neighborhood in a $5 \times 5$ structure in the SOFM1 model. 
TABLE 3: Seismic characteristics used in the study $[2,16]$.

\begin{tabular}{|c|c|c|c|}
\hline Number & Peak ground acceleration (PGA) & Earthquake name & Station \\
\hline 1 & 0.254 & Imperial Valley 1979 & Chihuahua \\
\hline 2 & 0.27 & Imperial Valley 1979 & Chihuahua \\
\hline 3 & 0.231 & Northridge 1994 & Hollywood Storage \\
\hline 4 & 0.145 & San Fernando 1971 & Lake Hughes \#1 \\
\hline 5 & 0.210 & San Fernando 1971 & Hollywood Stor Lot \\
\hline 6 & 0.134 & Superstition Hills 1987 & Wildlife LiquefactionArrey \\
\hline 7 & 0.134 & Superstition Hills 1987 & Wildlife iquefaction Arrey \\
\hline 8 & 0.119 & Superstition Hills 1987 & Salton Sea Wildlife Refuge \\
\hline 9 & 0.186 & Superstition Hills 1987 & Plaster City \\
\hline 10 & 0.247 & Superstition Hills 1987 & Calipatria Fire Station \\
\hline 11 & 0.135 & Landers 1992 & Barstow \\
\hline 12 & 0.385 & Cape Mendocino 1992 & Rio Dell Overpass \\
\hline 13 & 0.549 & Cape Mendocino 1992 & Rio Dell Overpass \\
\hline 14 & 0.164 & Coalinga 1983 & Parkfield-Fault Zone 3 \\
\hline 15 & 0.126 & Whittier Narrows 1987 & Beverly Hills \\
\hline 16 & 0.239 & Northridge, 1994 & LA, Baldwin Hills \\
\hline 17 & 0.143 & Imperial Valley, 1979 & El Centro Array \#12 \\
\hline 18 & 0.240 & Loma Prieta, 1989 & Anderson Dam Downstream \\
\hline 19 & 0.247 & Loma Prieta, 1989 & Anderson Dam Downstream \\
\hline 20 & 0.159 & Loma Prieta, 1989 & Agnews State Hospital \\
\hline 21 & 0.244 & Loma Prieta, 1989 & Anderson Dam Downstream \\
\hline 22 & 0.179 & Loma Prieta, 1989 & Coyote Lake Dam Downstream \\
\hline 23 & 0.309 & Imperial Valley, 1979 & Cucapah \\
\hline 24 & 0.207 & Loma Prieta, 1989 & Sunnyvale Colton Ave \\
\hline 25 & 0.117 & Imperial Valley, 1979 & El Centro Array \#13 \\
\hline 26 & 0.074 & Imperial Valley, 1979 & Westmoreland Fire Station \\
\hline 27 & 0.209 & Loma Prieta, 1989 & Sunnyvale Colton Ave \\
\hline 28 & 0.139 & Imperial Valley, 1979 & El Centro Array \#13 \\
\hline 29 & 0.110 & Imperial Valley, 1979 & Westmoreland Fire Station \\
\hline 30 & 0.269 & Loma Prieta, 1989 & Hollister Diff. Array \\
\hline
\end{tabular}

TABLE 4: Selected statistical characteristics of the parameters.

\begin{tabular}{|c|c|c|c|c|c|c|c|}
\hline Row & Parameter name & Unit & Parameter type & Minimum & Maximum & Average & Standard deviation \\
\hline 1 & $\begin{array}{c}\text { Peak ground } \\
\text { acceleration (PGA) }\end{array}$ & $\mathrm{m} / \mathrm{s}^{2}$ & Input & 0.074 & 0.549 & 0.207 & 0.095 \\
\hline 2 & $\begin{array}{l}\text { Input time of the } \\
\text { earthquake to a } \\
\text { structure }\end{array}$ & s & Input & 0.005 & 0.020 & 0.011 & 0.004 \\
\hline 3 & Time & $\mathrm{s}$ & Input & 21.880 & 39.990 & 36.187 & 5.896 \\
\hline 4 & Frequency & $\mathrm{Hz}$ & Input & 0.025 & 0.046 & 0.029 & 0.006 \\
\hline 5 & $\begin{array}{l}\text { Input acceleration } \\
\text { to the building } \\
\text { (Acc) }\end{array}$ & $\mathrm{m} / \mathrm{s}^{2}$ & Input & 0.100 & 1.500 & 0.795 & 0.406 \\
\hline 6 & Displacement & $\mathrm{mm}$ & Input & 11.025 & 1023.293 & 222.576 & 208.891 \\
\hline 7 & $\begin{array}{c}\text { Park \& Ang } \\
\text { damage index }\end{array}$ & - & Output & 0.008 & 0.823 & 0.153 & 0.138 \\
\hline
\end{tabular}


TABLE 5: The characteristics of the selected SOFM models.

\begin{tabular}{|c|c|c|c|c|c|c|c|c|c|}
\hline Row & $\begin{array}{l}\text { Model } \\
\text { name }\end{array}$ & $\begin{array}{c}\text { Number of } \\
\text { inputs }\end{array}$ & $\begin{array}{l}\text { Number of } \\
\text { outputs }\end{array}$ & $\begin{array}{c}\text { Number of } \\
\text { hidden layers }\end{array}$ & $\begin{array}{l}\text { Number of } \\
\text { nods in the } \\
\text { hidden layer }\end{array}$ & $\begin{array}{c}\text { Column and } \\
\text { Row in the } \\
\text { network }\end{array}$ & Training algorithm & $\begin{array}{l}\text { Transfer } \\
\text { function }\end{array}$ & $\begin{array}{c}\text { Neighborhood } \\
\text { shape }\end{array}$ \\
\hline 1 & SOFM 1 & & & 1 & 6 & $5 * 5$ & TanhAxon & Momentum & Square \\
\hline 2 & SOFM 2 & 6 & 1 & 2 & 8_4 & $6 * 6$ & LinearTanhAxon & Step & Line \\
\hline 3 & SOFM 3 & & & 3 & 4_4_4 & $7 * 7$ & LinearAxon & QuickProp & Diamond \\
\hline
\end{tabular}

TABLE 6: The optimized structure of SOFM models in training, validation, and testing.

\begin{tabular}{lccccccc}
\hline \multirow{2}{*}{ Number } & \multirow{2}{*}{ Model } & \multicolumn{3}{c}{ Training } & \multicolumn{2}{c}{ Validation } & \multicolumn{2}{c}{ Testing } \\
& & $R^{2}$ & Equation & $R^{2}$ & Equation & $R^{2}$ & Equation \\
\hline 1 & SOFM1 & 0.9216 & $y=0.9229 x+0.0128$ & 0.9330 & $y=0.9102 x+0.0133$ & 0.9213 & $y=0.9353 x+0.0118$ \\
2 & SOFM2 & 0.7590 & $y=0.7178 x+0.0483$ & 0.6703 & $y=0.7542 x+0.049$ & 0.8250 & $y=0.9174 x+0.0232$ \\
3 & SOFM3 & 0.6321 & $y=0.6561 x+0.0579$ & 0.5323 & $y=0.7059 x+0.0713$ & 0.6864 & $y=0.8166 x+0.0435$ \\
\hline
\end{tabular}

TABLE 7: Statistical results of different SOFM models.

\begin{tabular}{lcccccccccc}
\hline Number & Model & \multicolumn{3}{c}{ MAE } & \multicolumn{3}{c}{ MSE } & \multicolumn{2}{c}{ RMSE } \\
& & Training & Validation & Testing & Training & Validation & Testing & Training & Validation & Testing \\
\hline 1 & SOFM1 & 0.024 & 0.020 & 0.024 & 0.002 & 0.001 & 0.001 & 0.041 & 0.028 & 0.033 \\
2 & SOFM2 & 0.048 & 0.054 & 0.042 & 0.005 & 0.004 & 0.003 & 0.072 & 0.065 & 0.052 \\
3 & SOFM3 & 0.061 & 0.063 & 0.056 & 0.008 & 0.007 & 0.005 & 0.089 & 0.085 & 0.070 \\
\hline
\end{tabular}

form of LR, data is modeled using linear predictor functions. Unknown model parameters are then estimated from the data [16]. In LR, two or more independent variables have a major effect on the dependent variable shown in equation

$$
\begin{aligned}
& y=f\left(x_{1}, x_{2}, \ldots\right) \longrightarrow \\
& y=a_{0}+a_{1} x_{1}+a_{2} x_{2}+\cdots,
\end{aligned}
$$

where $y$ is the dependent variable; $x_{1}, x_{2}$, etc. are the independent variables; and $a_{1}, a_{2}, a_{3}$, etc. are the equation regression coefficients. In this research, various models of LR are investigated using MINITAB software. The best LR model, which was more coordinated with damage data, was obtained using

$$
Y=\left\{\begin{array}{lr}
-0.206-0.0246 X 1+0.449 X 2+0.00350 X 3+2.08 X 4+0.7635 X 5+0.000500 X 6 & \text { LR } 1 \\
0.174-0.0894 X 1+0.74 X 2-0.00278 X 3-4.71 X 4+0.28218 X 5 & \text { LR } 2 \\
0.572-0.1014 X 1+1.63 X 2-0.00589 X 3-7.12 X 4 & \text { LR 3. }
\end{array}\right.
$$

In the above equation, $Y$ is the damage to the entire frame, $X 1$ is the PGA variable, $X 2$ is the input time variable, $X 3$ is the time variable, $X 4$ is the frequency variable, $X 5$ is the acceleration variable, and $X 6$ is the displacement variable. The analysis results of the three LR models are presented in Table 8 and the results obtained from the statistical indices are presented in Table 9. Figure 6 shows the results arising from different LR models.

In the LR1 model, the values of $R^{2}$ are equal to 0.8925 , 0.9098 , and 0.8924 for training, validation, and testing, respectively. The values of MAE, MSE, and RMSE for the LR1 model are lower than those in the other two LR models.
5.2.2. Nonlinear Regression (NonLR). In nonlinear regression (NonLR), the PARK_ANG parameter $(y)$ is a dependent value and displacement $(x)$ is an independent value. The best NonLR model, which was more coordinated with damage data, was obtained via

Y

$$
= \begin{cases}0.5404 * \exp \left(-\left(\frac{(x-922.9)}{598}\right)^{2}\right) & \text { NonLR } 1 \\ 0.977 * \sin (0.0006597 * x+0.01211) & \text { NonLR 2. }\end{cases}
$$

The analysis results of the selected NonLR models are presented in Table 10 and the results obtained from the statistical 


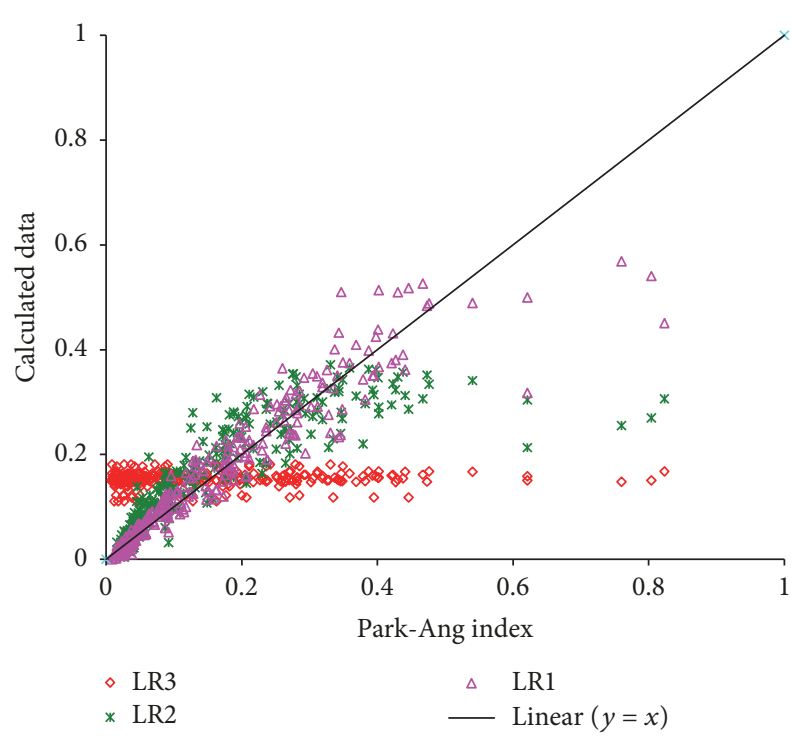

(a)

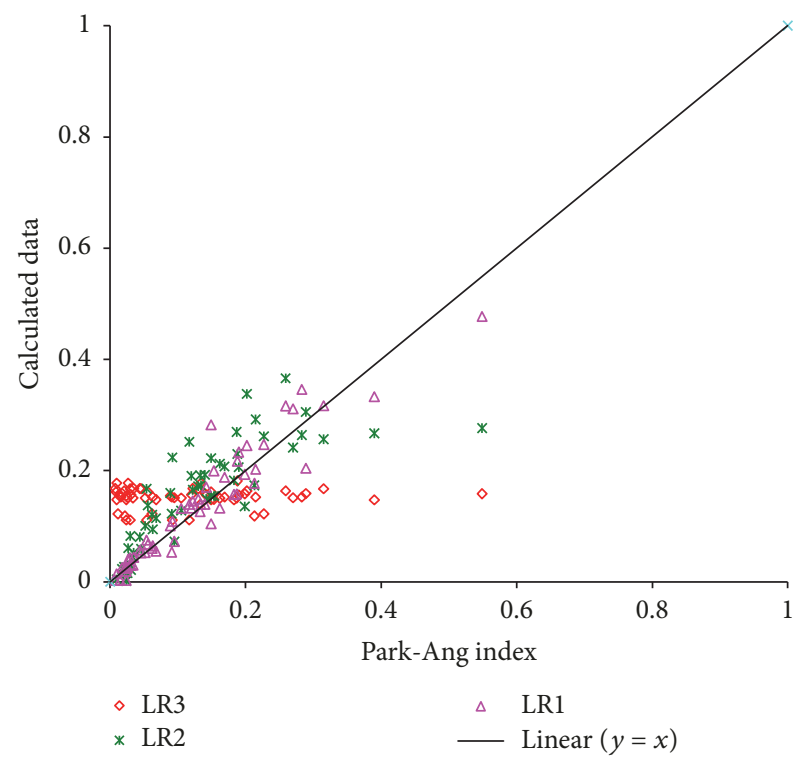

(b)

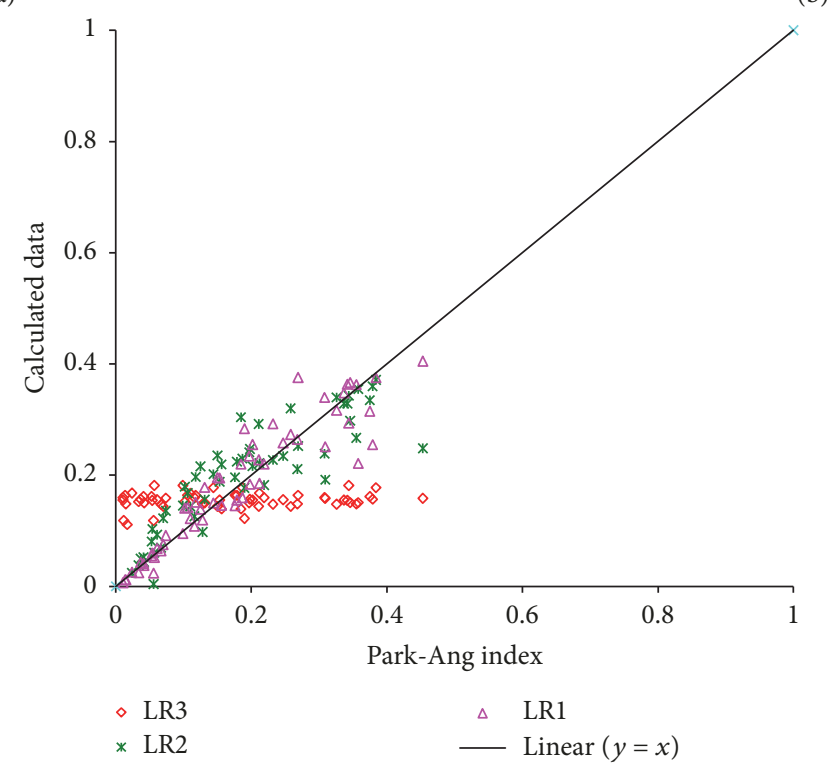

(c)

FIgURE 6: Comparison of the Park and Ang damage index obtained using LR and calculated data for (a) training, (b) validation, and (c) testing.

TABLE 8: The structure of LR models in training, validation, and testing.

\begin{tabular}{lcccccccc}
\hline \multirow{2}{*}{ Number Model } & \multirow{2}{*}{ Type } & \multicolumn{2}{c}{ Training } & \multicolumn{2}{c}{ Validation } & \multicolumn{2}{c}{ Testing } \\
& & \multirow{2}{*}{$R^{2}$} & Equation & $R^{2}$ & Equation & $R^{2}$ & Equation \\
\hline 1 & LR 1 & & 0.8924 & $y=0.8847 x+0.017$ & 0.9098 & $y=0.9715 x+0.0053$ & 0.8925 & $y=0.9319 x+0.0123$ \\
2 & LR 2 & Linear regression (LR) & 0.6883 & $y=0.6627 x+0.0486$ & 0.6693 & $y=0.826 x+0.035$ & 0.7946 & $y=0.845 x+0.032$ \\
3 & LR 3 & & 0.0096 & $y=0.0098 x+0.1509$ & 0.0062 & $y=0.0131 x+0.1494$ & 0.0241 & $y=0.0182 x+0.1515$ \\
\hline
\end{tabular}

TABLE 9: Statistical results of different LR models.

\begin{tabular}{|c|c|c|c|c|c|c|c|c|c|c|}
\hline \multirow{2}{*}{ Number } & \multirow{2}{*}{ Model } & \multicolumn{3}{|c|}{ MAE } & \multicolumn{3}{|c|}{ MSE } & \multicolumn{3}{|c|}{ RMSE } \\
\hline & & Training & Validation & Testing & Training & Validation & Testing & Training & Validation & Testing \\
\hline 1 & LR 1 & 0.027 & 0.023 & 0.026 & 0.002 & 0.001 & 0.002 & 0.048 & 0.033 & 0.039 \\
\hline 2 & LR 2 & 0.050 & 0.048 & 0.040 & 0.007 & 0.004 & 0.003 & 0.082 & 0.066 & 0.054 \\
\hline 3 & LR 3 & 0.114 & 0.089 & 0.099 & 0.021 & 0.012 & 0.014 & 0.145 & 0.111 & 0.118 \\
\hline
\end{tabular}



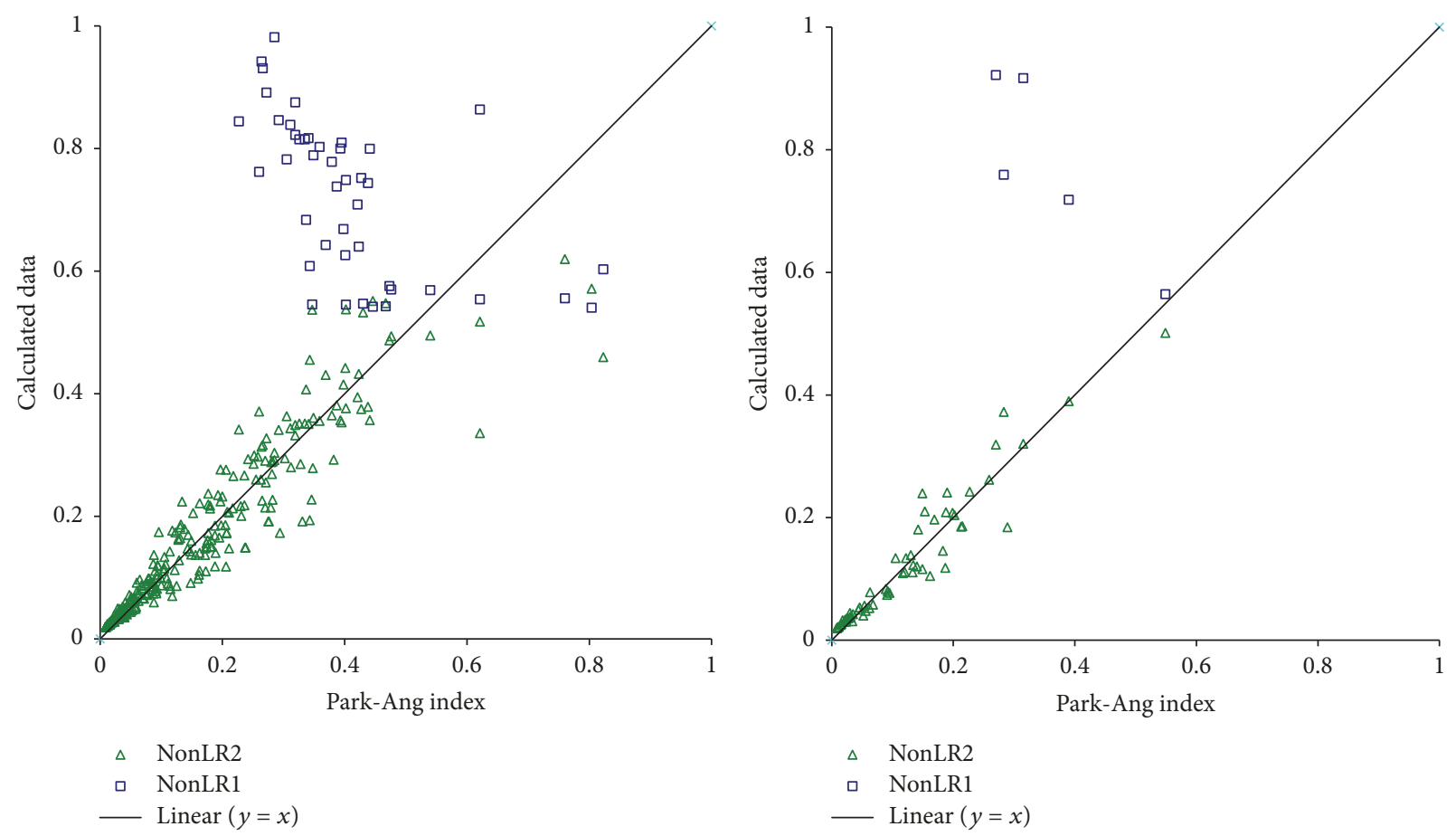

(a)

(b)

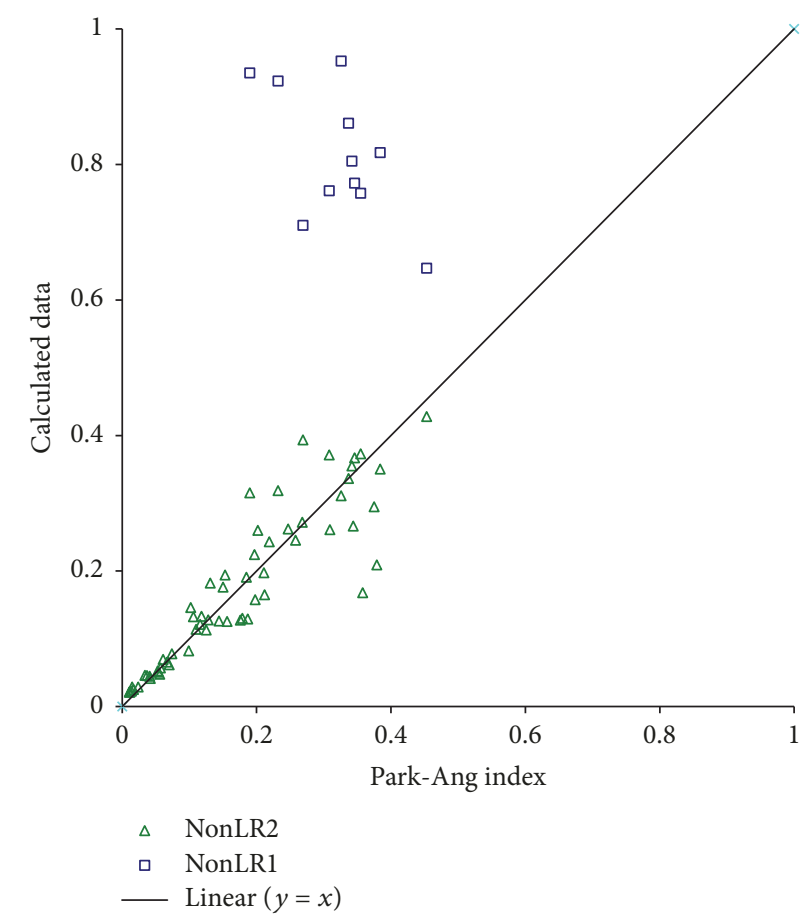

(c)

FIgURE 7: Comparison of the Park and Ang damage index obtained by NonLR and calculated data for (a) training, (b) validation, and (c) testing.

indices are presented in Table 11. Figure 7 shows the results arising from different NonLR models.

5.2.3. Summary of the Comparison. To determine the optimized structure of the radial basis function (RBF) neural network, version 5.0 of NeuroSolutions Software was used. The RBF with a structure of 6-1-4, the TanhAxon training algorithm, and the QuickProp transfer function were selected.

To evaluate the performance of the optimized SOFM1 model in assessing the Park and Ang damage, the obtained 


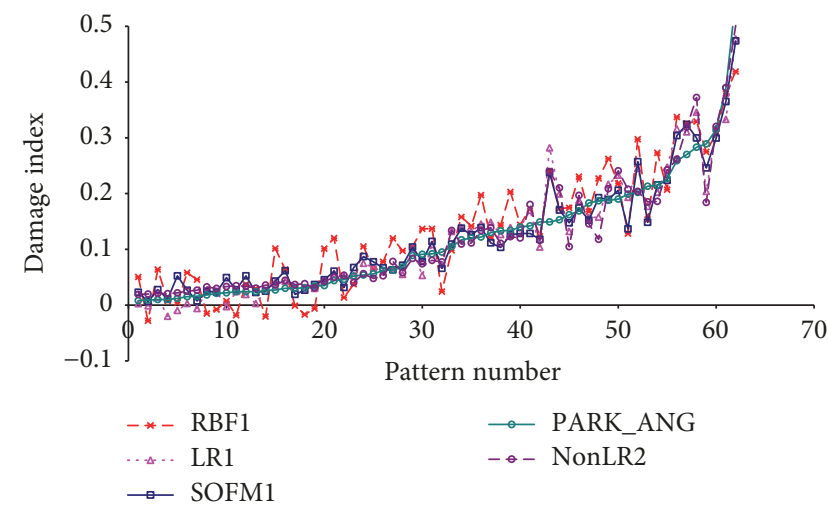

(a)

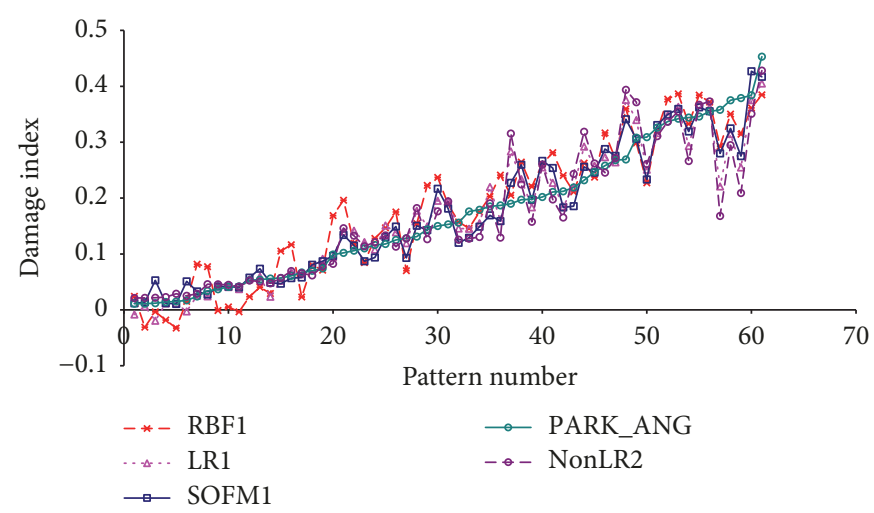

(b)

Figure 8: Comparison of the obtained results for (a) validation and (b) testing.

TABLE 10: Statistical results of different NonLR models.

\begin{tabular}{|c|c|c|c|c|}
\hline & Model & MAE & MSE & RMSE \\
\hline \multirow{2}{*}{ Training } & NonLR1 & 2.792 & 10.840 & 3.292 \\
\hline & NonLR2 & 0.030 & 0.003 & 0.051 \\
\hline \multirow{2}{*}{ Validation } & NonLR1 & 3.182 & 12.835 & 3.583 \\
\hline & NonLR2 & 0.021 & 0.001 & 0.031 \\
\hline \multirow{2}{*}{ Testing } & NonLR1 & 2.375 & 8.372 & 2.894 \\
\hline & NonLR2 & 0.031 & 0.002 & 0.050 \\
\hline
\end{tabular}

TABLE 11: The structure of NonLR models in training, validation, and testing.

\begin{tabular}{|c|c|c|c|c|c|c|c|c|}
\hline \multirow{2}{*}{ Number } & \multirow{2}{*}{ Model } & \multirow{2}{*}{ Type } & \multicolumn{2}{|r|}{ Training } & \multicolumn{2}{|r|}{ Validation } & \multicolumn{2}{|r|}{ Testing } \\
\hline & & & $R^{2}$ & Equation & $R^{2}$ & Equation & $R^{2}$ & Equation \\
\hline 1 & NonLR 1 & $\begin{array}{l}\text { Nonlinear } \\
\text { regression }\end{array}$ & 0.7351 & $y=-9.5762 x+4.4271$ & 0.8014 & $y=-13.122 x+4.85$ & 0.7925 & $y=-11.403 x+4.5353$ \\
\hline 2 & NonLR 2 & (NonLR) & 0.8781 & $y=0.8708 x+0.0203$ & 0.9174 & $y=0.9506 x+0.0083$ & 0.8272 & $y=0.878 x+0.0191$ \\
\hline
\end{tabular}

TABle 12: Structure of different models for assessing the Park \& Ang damage.

\begin{tabular}{lccccccc}
\hline \multirow{2}{*}{ Number } & \multirow{2}{*}{ Model } & \multicolumn{2}{c}{ Training } & \multicolumn{2}{c}{ Validation } & \multicolumn{2}{c}{ Testing } \\
& & $R^{2}$ & Equation & $R^{2}$ & Equation & $R^{2}$ & Equation \\
\hline 1 & SOFM1 & 0.9216 & $y=0.9229 x+0.0128$ & 0.933 & $y=0.9102 x+0.0133$ & 0.9213 & $y=0.9353 x+0.0118$ \\
2 & LR1 & 0.8924 & $y=0.8847 x+0.017$ & 0.9098 & $y=0.9715 x+0.0053$ & 0.8925 & $y=0.9319 x+0.0123$ \\
3 & RBF & 0.8054 & $y=0.8151 x+0.0238$ & 0.8304 & $y=0.9509 x+0.0187$ & 0.8789 & $y=0.9784 x+0.0122$ \\
4 & NonLR2 & 0.8781 & $y=0.8708 x+0.0203$ & 0.9174 & $y=0.9506 x+0.0083$ & 0.8272 & $y=0.878 x+0.0191$ \\
\hline
\end{tabular}

results were compared with the results derived from the SOFM, LR models, RBF network, and NonLR. This comparison was conducted in three steps of training, testing, and validation. The obtained results are shown in Table 12. Statistical results of different models are presented in Table 13. In Figure 8, a comparison of the obtained results for validation and testing is presented.

When considering $R^{2}$ coefficient, the slope of the straight line and statistical indices in each of the three models, it can be concluded that the accuracy of the SOFM1 model is higher than the accuracy of the other two LR models and also the RBF network in the case of training, validation, and test steps.

\section{Conclusion}

In this paper, the self-organizing feature map (SOFM) was used to evaluate damage in reinforced concrete frames with shear walls. For this purpose, a concrete frame with a shear wall was subjected to nonlinear dynamic analysis. The extent of damage to the frame was calculated using the Park and Ang index.

The SOFM was optimized using the genetic algorithm (GA) in order to determine the number of layers, number of nodes in the hidden layer, transfer function type, and learning algorithm. The obtained model was compared with linear 
TABLE 13: Statistical results of different models.

\begin{tabular}{lcccccccccc}
\hline Number & Model & \multicolumn{3}{c}{ MAE } & \multicolumn{3}{c}{ MSE } & \multicolumn{2}{c}{ RMSE } \\
& & Training & Validation & Testing & Training & Validation & Testing & Training & Validation & Testing \\
\hline 1 & SOFM1 & 0.024 & 0.020 & 0.024 & 0.002 & 0.001 & 0.001 & 0.041 & 0.028 & 0.033 \\
2 & LR1 & 0.027 & 0.023 & 0.026 & 0.002 & 0.001 & 0.002 & 0.048 & 0.033 & 0.039 \\
3 & RBF & 0.043 & 0.039 & 0.036 & 0.004 & 0.002 & 0.002 & 0.064 & 0.048 & 0.044 \\
4 & NonLR2 & 0.030 & 0.021 & 0.031 & 0.003 & 0.001 & 0.002 & 0.051 & 0.031 & 0.050 \\
\hline
\end{tabular}

regression (LR) and nonlinear regression (NonLR) models and also the radial basis function (RBF) neural network. It can be concluded that the SOFM that is optimized with GA enjoys more strength, flexibility, and accuracy.

\section{Conflicts of Interest}

The authors declare that there are no conflicts of interests regarding the publication of this paper.

\section{References}

[1] G. De Schutter, Damage to Concrete Structures, CRC Press, Florida, Fla, USA, 2012.

[2] M. Nikoo, P. Zarfam, and M. Nikoo, "Determining displacement in concrete reinforcement building with using evolutionary artificial neural networks," World Applied Sciences Journal, vol. 16, no. 12, pp. 1699-1708, 2012.

[3] M. Nikoo, F. Torabian Moghadam, and Ł. Sadowski, "Prediction of concrete compressive strength by evolutionary artificial neural networks," Advances in Materials Science and Engineering, vol. 2015, Article ID 849126, 8 pages, 2015.

[4] E. M. Güneyisi, M. D’Aniello, R. Landolfo, and K. Mermerdaş, "Prediction of the flexural overstrength factor for steel beams using artificial neural network," Steel and Composite Structures, vol. 17, no. 3, pp. 215-236, 2014.

[5] E. M. Güneyisi, M. Gesoğlu, E. Güneyisi, and K. Mermerdaş, "Assessment of shear capacity of adhesive anchors for structures using neural network based model," Materials and Structures, vol. 49, no. 3, pp. 1065-1077, 2016.

[6] M. Nikoo, P. Zarfam, and H. Sayahpour, "Determination of compressive strength of concrete using Self Organization Feature Map (SOFM)," Engineering with Computers, vol. 31, no. 1, pp. 113-121, 2015.

[7] F. Khademi, S. M. Jamal, N. Deshpande, and S. Londhe, "Predicting strength of recycled aggregate concrete using artificial neural network, adaptive neuro-fuzzy inference system and multiple linear regression," International Journal of Sustainable Built Environment, vol. 5, no. 2, pp. 355-369, 2016.

[8] F. Khademi, M. Akbari, S. M. Jamal, and M. Nikoo, "Multiple linear regression, artificial neural network, and fuzzy logic prediction of 28 days compressive strength of concrete," Frontiers of Structural and Civil Engineering, vol. 11, no. 1, pp. 90-99, 2017.

[9] T. Kohonen, Self-Organization and Associative Memory, Springer, Berlin, Germany, 1988.

[10] Ł. Sadowski, M. Nikoo, and M. Nikoo, "Principal component analysis combined with a self organization feature map to determine the pull-off adhesion between concrete layers," Construction and Building Materials, vol. 78, pp. 386-396, 2015.
[11] D. E. Goldberg and J. H. Holland, "Genetic algorithms and machine learning," Machine Learning, vol. 3, no. 2-3, pp. 95-99, 1998.

[12] Z. Liu, A. Liu, C. Wang, and Z. Niu, "Evolving neural network using real coded genetic algorithm (GA) for multispectral image classification," Future Generation Computer Systems, vol. 20, no. 7, pp. 1119-1129, 2004.

[13] R. Valles, A. Reinhorn, S. Kunnath, C. Li, and A. Mandan, "Idarc2d version 6.0: a computer program for the inelastic damage analysis of building," Tech. Rep. Nceer-96-0010, 1996.

[14] G. Srinivas, P. Vasanth, and T. Miroslav, "Self-organizing feature map with improved performance by non-monotonic variation of the learning rate," November, 2005, Freepatentsonline (FPO).

[15] Y. J. Park, A. M. Reinhorn, and S. K. Kunnath, "IDARC: inelastic damage analysis of reinforced concrete frame-shearwall structures," Tech. Rep. NCEER-87-0008, State University of New York at Buffalo, Buffalo, NY, USA, 1987.

[16] M. Nikoo and P. Zarfam, "Determining confidence for evaluation of vulnerability in reinforced concrete frames with shear wall," Journal of Basic and Applied Scientif $\dot{x}$ Research, vol. 2, no. 7, pp. 6605-6614, 2012. 

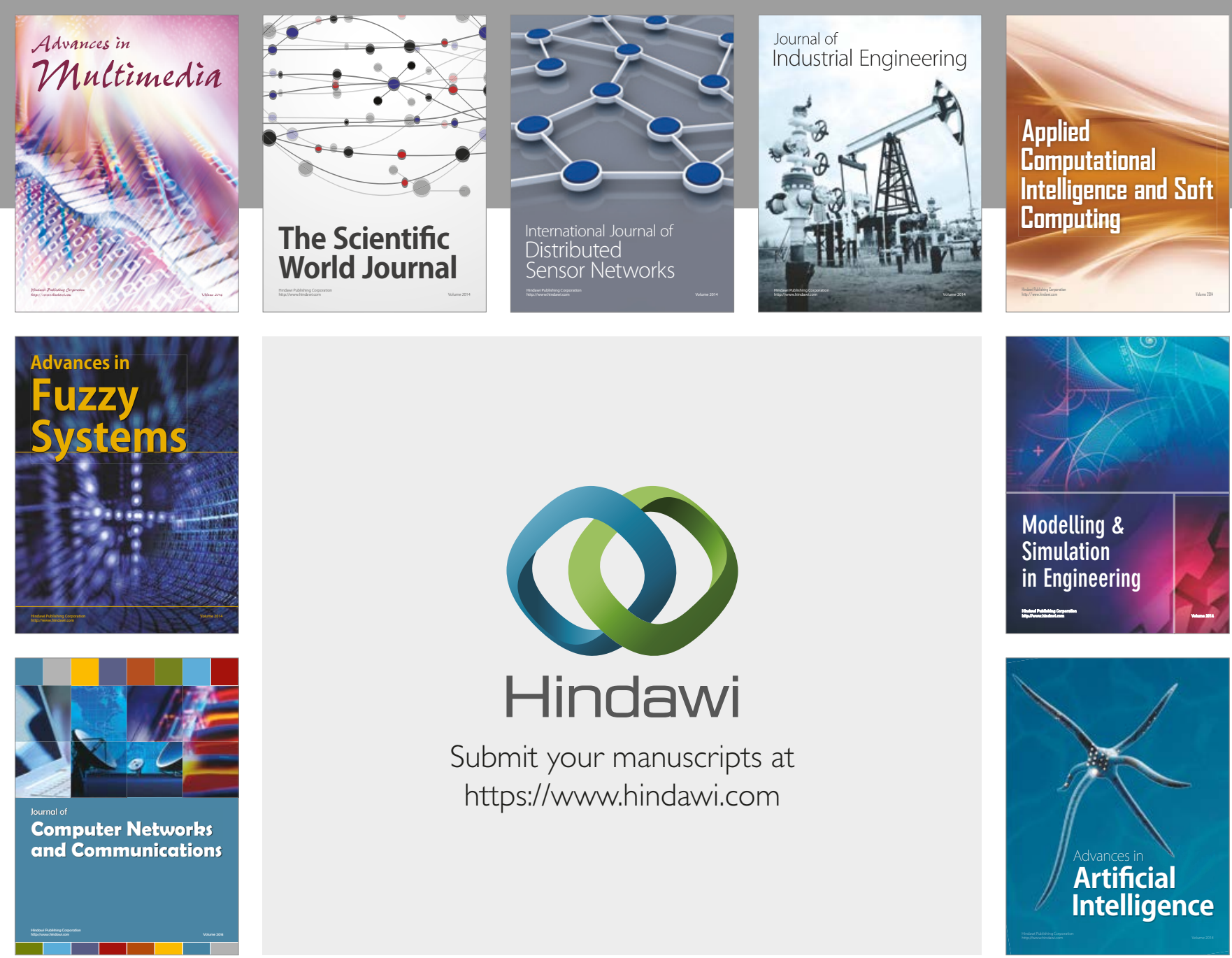

\section{Hindawi}

Submit your manuscripts at

https://www.hindawi.com
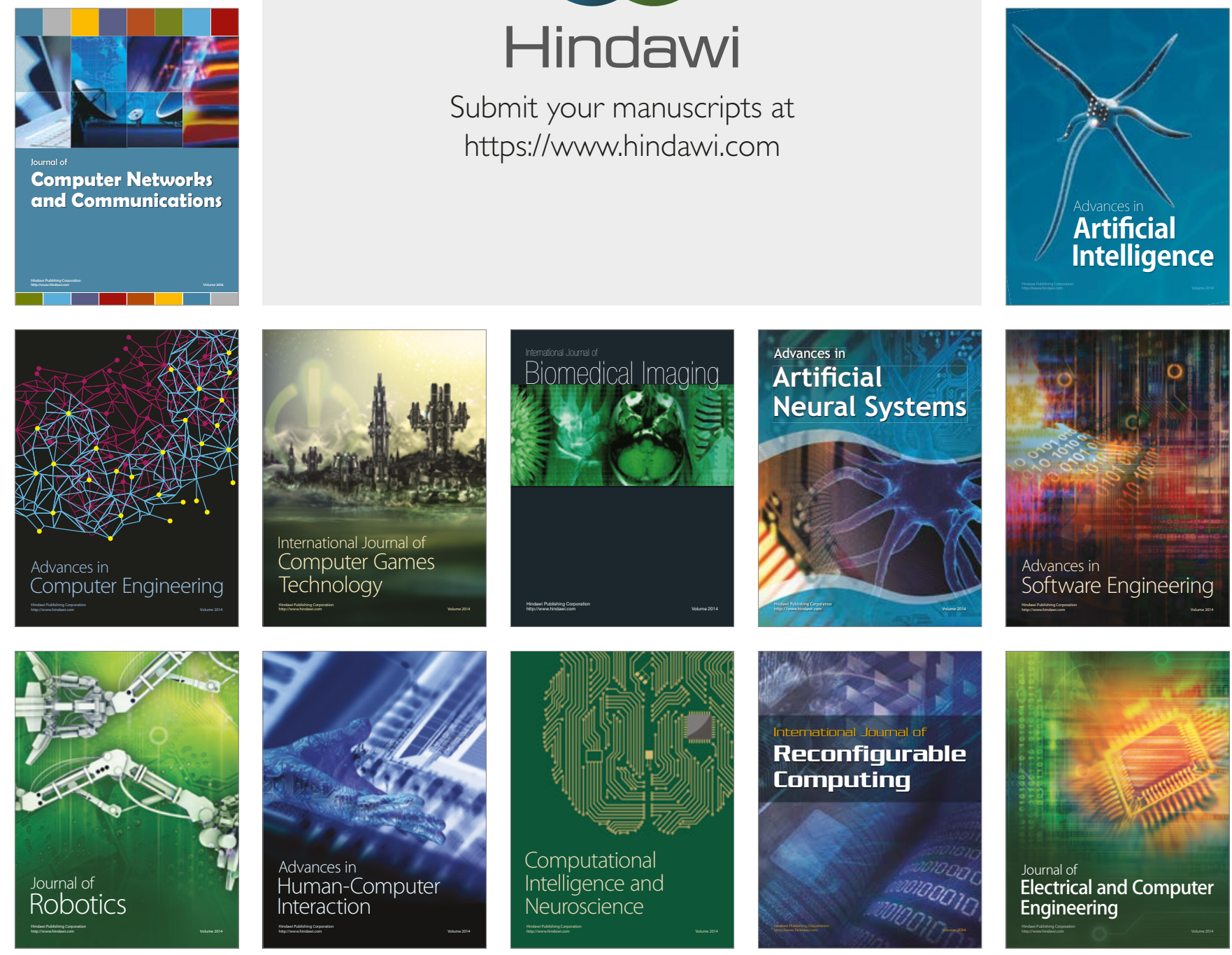